\title{
Short communication: Presence of G protein-coupled receptor 43 in rumen epithelium but not in the islets of Langerhans in cattle
}

\author{
A. Wang, ${ }^{\star}$ R. M. Akers, $†$ and H. Jiang ${ }^{* 1}$ \\ *Department of Animal and Poultry Sciences, and \\ †Department of Dairy Science, Virginia Tech, Blacksburg 24061
}

\begin{abstract}
Volatile fatty acids (VFA) are the major products of microbial fermentation in the rumen. Besides serving as substrates for energy generation, VFA are known to stimulate rumen development, increase serum insulin and glucagon concentrations, and regulate gene expression in cattle and sheep. The mechanisms underlying these regulatory effects of VFA are unknown, but the recent discovery that VFA can bind to G protein-coupled receptor 43 (GPR43) and 41 (GPR41) suggests that the regulatory effects of VFA may be mediated by these receptors. As a step toward testing this possibility, we determined whether GPR43 was expressed in bovine rumen wall and the pancreatic islets of Langerhans. Polyclonal antibody against a bovine GPR43 peptide was generated. The specificity of the antibody for bovine GPR43 was confirmed by Western blot analysis of recombinant bovine GPR43 protein. Immunohistochemical analyses using this antibody revealed the presence of GPR43-immunoreactive cells in the epithelium, but not in the other layers of cattle rumen wall. The same immunohistochemical analyses did not reveal GPR43-immunoreactive cells in the islets of Langerhans or the surrounding exocrine tissue of cattle pancreas. These data support the possibility that the effect of VFA on rumen epithelial growth in cattle is directly mediated by GPR43 in the rumen epithelial cells and that the effect of VFA on pancreatic secretion of insulin and glucagon in cattle is unlikely to be directly mediated by GPR43.
\end{abstract}

Key words: volatile fatty acid, rumen, pancreas, cattle

\section{Short Communication}

Volatile fatty acids are a group of short-chain fatty acids, containing 1 to 7 carbons, produced by microbial fermentation in the gastrointestinal tract (Bergman,

Received August 30, 2011.

Accepted November 3, 2011.

${ }^{1}$ Corresponding author: hojiang@vt.edu
1990). The major VFA are acetate, propionate, and butyrate. Volatile fatty acids are a major source of energy for the animal, in particular, the ruminant (Bergman, 1990). In ruminants, microbial fermentation occurs mainly in the rumen, and rumen VFA are estimated to provide 60 to $70 \%$ of the energy requirement of a steer (Siciliano-Jones and Murphy, 1989). In addition to serving as substrates for energy production, VFA have a multitude of regulatory effects (Bergman, 1990). Intraruminal administration or dietary supplementation of VFA stimulates the growth of rumen epithelium in young ruminants (Sakata and Tamate, 1978; Lane and Jesse, 1997; Gorka et al., 2009), and increases blood insulin and glucagon concentrations (Bergman, 1990; Harmon, 1992; Kristensen and Harmon, 2004). Volatile fatty acids regulate the expression of hundreds of genes in various types of cells (Li and Elsasser, 2005; $\mathrm{Li}$ and Li, 2006; Alvaro et al., 2008). The mechanisms underlying these regulatory effects of VFA are unclear. It was recently discovered that VFA can bind to $\mathrm{G}$ protein-coupled receptors 43 (GPR43) and 41 (GPR41), which are also named free fatty acid receptor 2 and 3, respectively (Brown et al., 2003; Le Poul et al., 2003; Nilsson et al., 2003). This suggests that the regulatory effects of VFA, such as those on rumen epithelium growth and pancreatic secretion of insulin and glucagon, may be directly mediated by GPR 43 and GPR41. As a step toward testing this possibility, we produced and validated a polyclonal antibody specific for the bovine GPR43 protein and used this antibody to determine if and where GPR43 protein was present in the rumen and the pancreas of cattle.

A commercially available GPR43 antibody (Santa Cruz Biotechnology, Santa Cruz, CA), which was raised against a human GPR43 peptide, did not cross-react with bovine GPR43 (bGPR43) by Western blot analysis (data not shown). We therefore aimed to generate antibody using a bGPR43 peptide as antigen. The sequence of the peptide is EDPGVSQAEGAPSS, which corresponds to the 311 to 324 region of the bGPR43 protein (GenBank accession number NP_001157256.1). This peptide was chosen as antigen based on its predicted high antigenicity. The peptide was conjugated 
to keyhole limpet hemocyanin through an added Nterminal cysteine and injected into rabbits following a standard polyclonal antibody production procedure (Diano et al., 1987). The antibody was affinity-purified using protein A columns. The titer of the purified antibody was determined by ELISA to be 1:512,000. The steps from peptide synthesis to ELISA were contracted to GenScript (Piscataway, NJ).

To determine if the generated bGPR43 antibody reacted with bovine GPR43 protein, we amplified the entire coding region of bGPR $43 \mathrm{cDNA}$ by PCR, using forward primer 5'-tgcaagcttCAGCCATGCCAGACTGGGATAG- ${ }^{\prime}$ and reverse primer 5'-GATGGATCC-TCCAAGCCTGCTCAACTCCT-3' . The PCR product was cloned into the enhanced green fluorescent protein (EGFP) tagging vector pEGFP-C1 (Clontech, Mountain View, CA). The resulting plasmid pEGFP-bGPR43 was confirmed by DNA sequencing. We transfected pEGFP-bGPR43 or pEGFP-C1 into Chinese hamster ovary (CHO) cell line cells using FuGene 6 as transfection reagent (Roche, Indianapolis, $\mathrm{IN})$. The cells were cultured for $48 \mathrm{~h}$ at $37^{\circ} \mathrm{C}$ under $5 \% \mathrm{CO}_{2}$ in minimum essential medium supplemented with $10 \%$ fetal bovine serum, $100 \mathrm{U} / \mathrm{mL}$ penicillin, and $100 \mu \mathrm{g} / \mathrm{mL}$ streptomycin (Sigma, St. Louis, MO), and then lysed as described previously (Zhou et al., 2008). Thirty micrograms of total protein lysate was separated by SDS-PAGE, and subsequently transferred to a nitrocellulose membrane as described previously (Wang et al., 2009). The membranes were incubated with the bGPR43 antibody at a dilution of 1:2,500 or a green fluorescent protein (GFP) antibody (Sigma-
Aldrich, St. Louis, MO) at dilution of 1:1,000, and then a horseradish peroxidase-conjugated donkey anti-rabbit secondary antibody at dilution of 1:1000 (Santa Cruz Biotechnology). We also performed an absorption test to validate the specificity of the bGPR 43 antibody. In this test, the bGPR43 antibody was incubated with a 100-fold molar excess of the bGPR43 peptide for $1 \mathrm{~h}$ at room temperature before being incubated with the membrane.

Representative images of Western blot analyses are shown in Figure 1. The bGPR43 antibody detected a protein of approximately $65 \mathrm{kDa}$ from $\mathrm{CHO}$ cells transfected with the pEGFP-bGPR43 plasmid but not from $\mathrm{CHO}$ cells without transfection or $\mathrm{CHO}$ cells transfected with pEGFP-C1 (Figure 1A). The approximate size of this protein matched the calculated molecular weight of the bGPR43-EGFP fusion protein $(36 \mathrm{kDa}$ for bGPR43 + $27 \mathrm{kDa}$ for EGFP). The same protein was also detected by a GFP antibody (Figure 1B). These findings suggest that the protein detected by the bGPR43 antibody was the bGPR43-EGFP fusion protein, and this in turn suggests that the bGPR43 antibody cross-reacts with bovine GPR43 protein. Preincubation of the bGPR43 antibody with an excess of its antigen blocked the detection of the bGPR43-EGFP fusion protein (Figure 1C). This data validated the specificity of the bGPR 43 antibody for the bGPR 43 peptide.

We next used this antibody in immunohistochemistry (IHC) to localize GPR43 in bovine rumen and pancreas tissues. Rumen (ventral sac) and pancreas tissues from adult cattle were collected at slaughter, fixed with $10 \%$
A

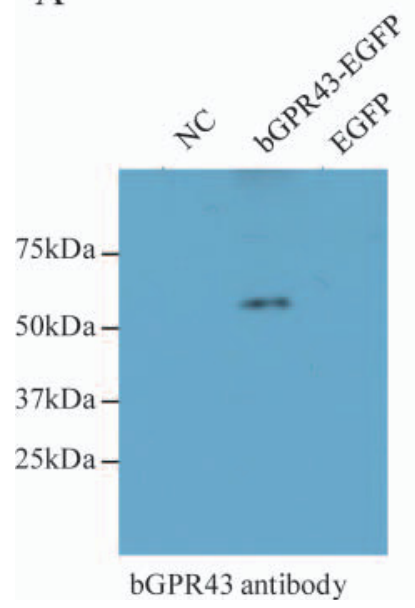

B

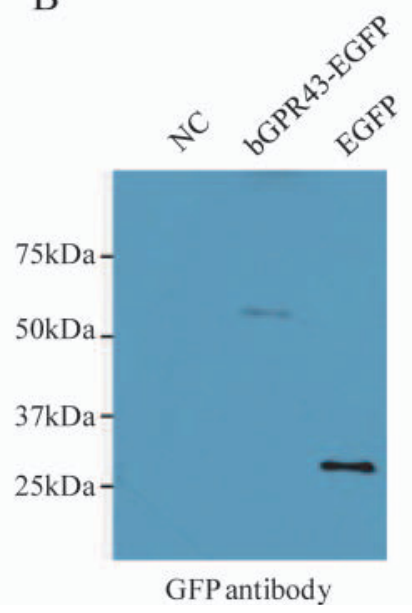

C

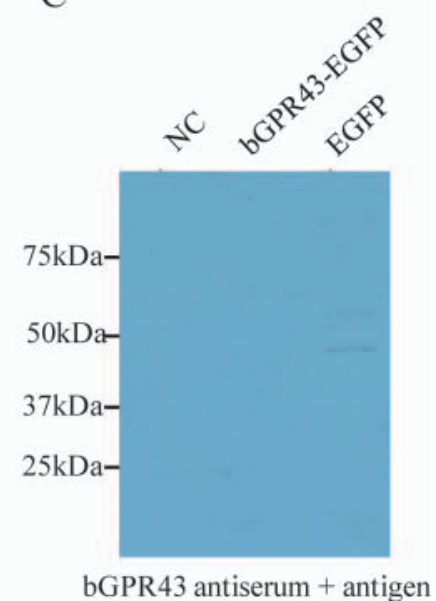

Figure 1. Confirmation of the specificity of the bovine G protein-coupled receptor 43 (bGPR43) antibody for bovine GPR43 protein. Equal

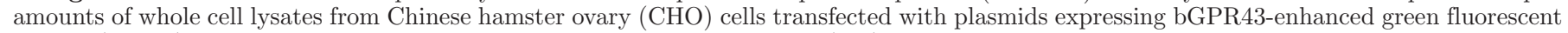

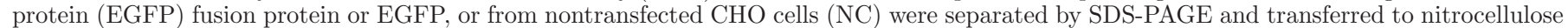

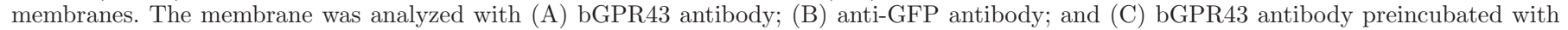
an excess of the bGPR43 peptide. Color version available in the online PDF. 

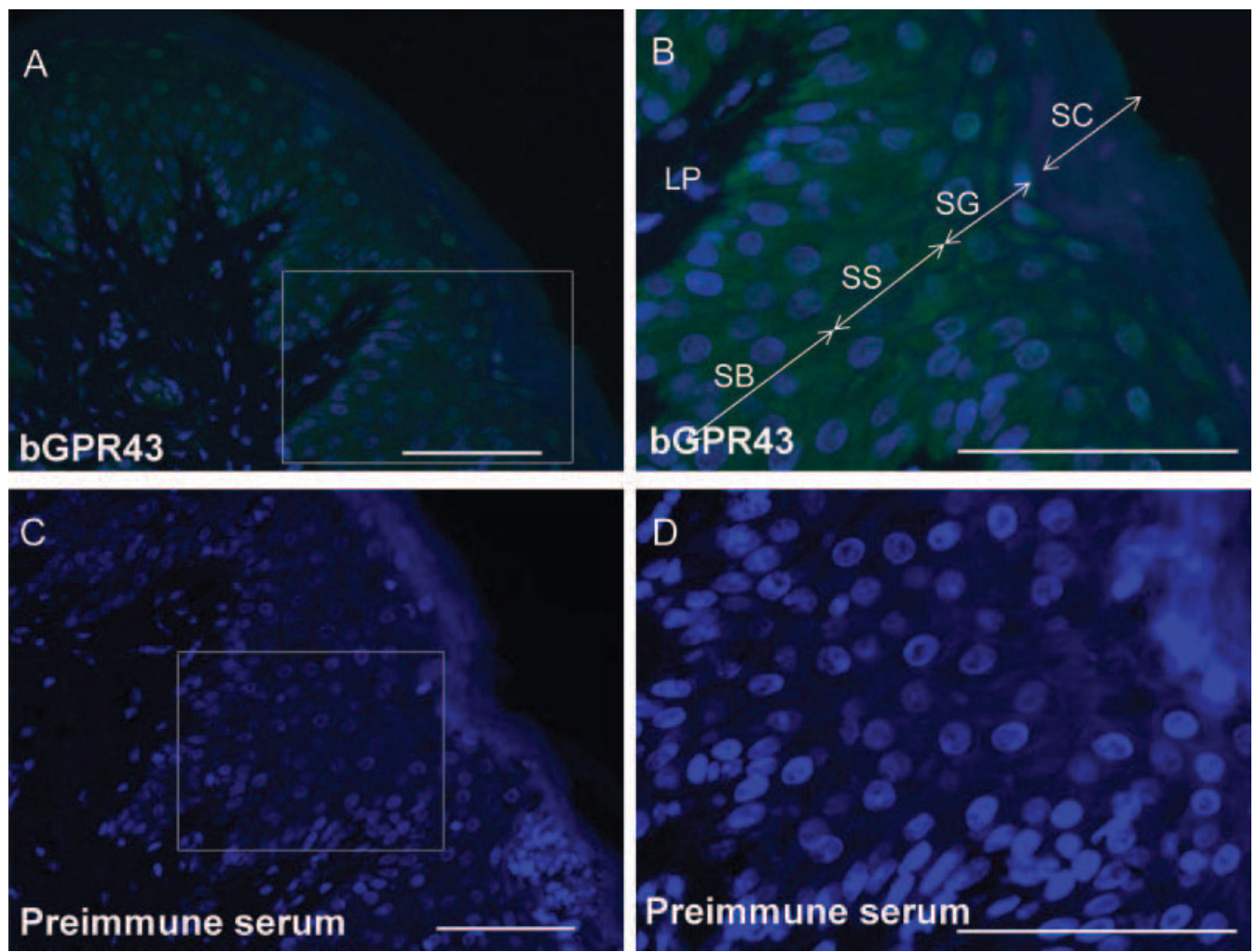

Figure 2. Immunohistochemistry of G protein-coupled receptor 43 (GPR43) in cattle rumen. Rumen sections were incubated first with the bovine GPR43 antibody (bGPR43; A and B) or preimmune rabbit serum (C and D) and then with Alexa Fluor 488-tagged secondary antibody. The sections were counterstained with 4',6-diamidino-2-phenylindole (DAPI) to label the nuclei. Immunoreactive signals were visualized with a fluorescence microscope (A and C) in adjacent sections of a partial papilla (B and D show higher magnifications of the boxed regions in A and C, respectively). GPR43 staining is labeled in green: DAPI staining is labeled in blue. SC = stratum corneum; SG = stratum granulosum: SS $=$ stratum spinosum; $\mathrm{SB}=$ stratum basale; $\mathrm{LP}=$ lamina propria. $\mathrm{Bar}=100 \mu \mathrm{m}$.
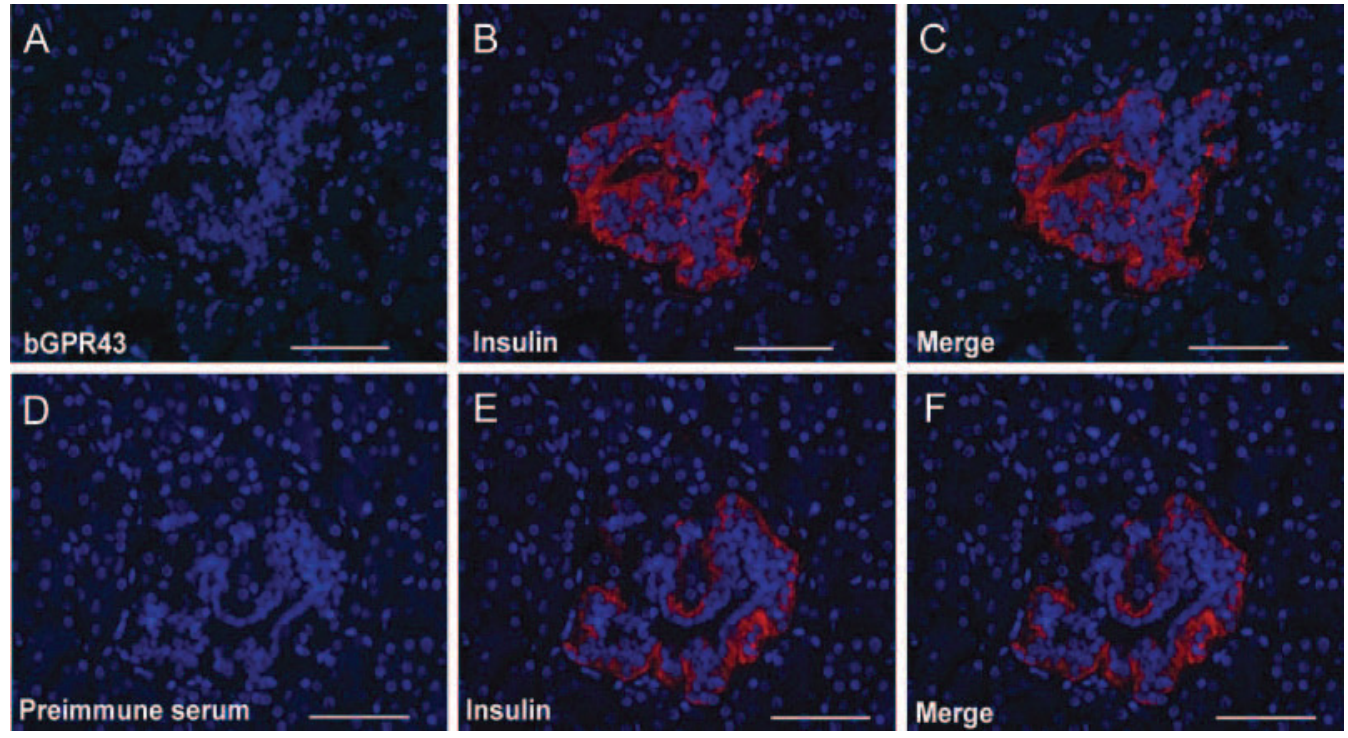

Figure 3. Immunohistochemistry of G protein-coupled receptor 43 (GPR43) and insulin in cattle pancreas. Pancreas sections were doubleincubated with bovine GPR43 antibody (bGPR43) or preimmune rabbit serum and anti-insulin antibody, and then secondary antibodies labeled with Alexa Fluor 488 and Alexa Fluor 594, respectively. The GPR43-immunoreactive cells, if present, would appear in green and the insulinimmunoreactive cells in red, and the nuclei were stained with 4',6-diamidino-2-phenylindole (DAPI, blue). (A) GPR43 staining in a section; (B) insulin staining in the same section; (C) merger of A and B; (D), (E), and (F) show analysis of an adjacent section using preimmune rabbit serum instead of bGPR43 antibody. Bar $=100 \mu \mathrm{m}$. 
neutral buffered formalin (Fisher Scientific, Pittsburgh, $\mathrm{PA}$ ), and embedded in paraffin. Sections of $5 \mu \mathrm{m}$ were cut with a microtome. The sections were deparaffinized in xylene and rehydrated in a graded series of ethanol and PBS as described previously (Capuco et al., 2002; Berry et al., 2003). Antigen retrieval was performed by steaming the sections in $10 \mathrm{~m} M$ citrate buffer ( $\mathrm{pH} 6.0)$ for $35 \mathrm{~min}$ and cooling at room temperature $\left(25^{\circ} \mathrm{C}\right)$ for $10 \mathrm{~min}$. The sections were incubated with $10 \%$ nonimmune goat serum for $30 \mathrm{~min}$ to block nonspecific binding of antibody.

For IHC of the rumen tissue, the sections were incubated with the bGPR43 antibody at a dilution of 1:1,000 in a humidifying chamber at $4^{\circ} \mathrm{C}$ overnight. Following rinsing in PBS, the sections were incubated with Alexa 488-tagged goat-anti-rabbit secondary antibody (Invitrogen, Carlsbad, CA) at a dilution of 1:200 in the dark for $60 \mathrm{~min}$. For IHC of the pancreatic tissue, the sections were doubly incubated with the bGPR43 antiserum at 1:1,000 and mouse anti-insulin antibody at 1:2,000 (Sigma-Aldrich) at $4^{\circ} \mathrm{C}$ overnight. These 2 primary antibodies were detected, respectively, by Alexa Fluor 488-tagged goat anti-rabbit antibody at 1:200 and Alexa Fluor 594-tagged goat anti-mouse secondary antibody at 1:200 (Invitrogen). Following rinsing in PBS, the sections were mounted with ProLong Gold antifade reagent containing 4',6-diamidino-2-phenylindole (DAPI, Invitrogen) to stain the nuclei. The sections were examined with a fluorescence microscope. Adjacent sections with the bGPR43 antibody replaced by rabbit preimmune serum or the bGPR43 antibody omitted served as negative controls.

Representative images of the IHC analyses are presented in Figure 2 and Figure 3. The IHC of rumen sections revealed GPR43 immunostaining in the epithelium layer (labeled in green in Figure 2A, 2B), but not in the lamina propria (Figure 2A, 2B), submucosa, or muscular layers (images not shown). Within the epithelium, GPR43 immunostaining was much stronger in the stratum basale, stratum granulosum, and stratum spinosum than in the stratum corneum (Figure 2B). The specificity of GPR43 immunostaining is supported by the lack of the staining in sections incubated with rabbit preimmune serum (Figure 2C, 2D) or in sections incubated without the GPR43 antibody (images not shown). The IHC of the pancreas sections did not reveal GPR43 immunostaining in either the islets of Langerhans or their surrounding tissue (Figure 3). As expected, insulin-immunoreactive cells (i.e., the $\beta$ cells) were detected in the islets of Langerhans (labeled in red in Figure 3), but not in the exocrine part of the pancreas (Figure 3).

Given the fact that GPR43 is present in the epithelium of human and rat colon (Karaki et al., 2006, 2008;
Kaji et al., 2011; Tang et al., 2011) and that GPR43 mRNA is expressed in the epithelium of bovine rumen (Wang et al., 2009), it is not surprising that GPR43 is also expressed in the epithelium of bovine rumen, because the rumen in cattle and colon in humans and rats are the primary sites where short-chain fatty acids are produced and absorbed (Bergman, 1990). However, it is surprising that GPR43 protein was not detected in bovine pancreas, as GPR43 mRNA was expressed in this tissue (Wang et al., 2009). Either GPR43 mRNA is not translated efficiently to protein in bovine pancreas, or expression of GPR43 protein in this tissue is insufficient to be detectable by IHC.

The stimulatory effects of VFA on growth of rumen epithelium and pancreatic secretion of insulin and glucagon are well established (Sakata and Tamate, 1978; Bergman, 1990; Harmon, 1992; Lane and Jesse, 1997; Kristensen and Harmon, 2004; Gorka et al., 2009). The presence of GPR43, the receptor for VFA (Brown et al., 2003; Le Poul et al., 2003; Nilsson et al., 2003; Wang et al., 2009), in the epithelium of cattle rumen supports a potential role of GPR43 in directly mediating the effects of VFA on rumen epithelial growth. The mechanisms by which VFA stimulates growth of rumen epithelium through GPR43 remain to be studied. We speculate that binding of VFA to GPR43 might change the expression or activity of cell cycle regulators, enhance the responsiveness to endocrine or paracrine growth factors, or increase the uptake of VFA (and hence increased energy production) in rumen epithelial cells, among many other possibilities. On the contrary, the absence of GPR43 immunoreactive cells in the pancreas does not support a role of GPR43 in directly mediating the stimulatory effects of VFA on pancreatic secretion of insulin and glucagon in cattle.

\section{ACKNOWLEDGMENTS}

The authors thank Lee Johnson (Department of Animal and Poultry Sciences, Virginia Tech, Blacksburg) and Cathy Parsons (Department of Dairy Science, Virginia Tech, Blacksburg) for excellent technical assistance. This work was supported by National Research Initiative Competitive Grant no. 2007-35206-17839 from the USDA Cooperative State Research, Education, and Extension Service.

\section{REFERENCES}

Alvaro, A., R. Sola, R. Rosales, J. Ribalta, A. Anguera, L. Masana, and J. C. Vallve. 2008. Gene expression analysis of a human enterocyte cell line reveals downregulation of cholesterol biosynthesis in response to short-chain fatty acids. IUBMB Life 60:757-764.

Bergman, E. N. 1990. Energy contributions of volatile fatty acids from the gastrointestinal tract in various species. Physiol. Rev. $70: 567-590$. 
Berry, S. D., R. D. Howard, and R. M. Akers. 2003. Mammary localization and abundance of laminin, fibronectin, and collagen IV proteins in prepubertal heifers. J. Dairy Sci. 86:2864-2874.

Brown, A. J., S. M. Goldsworthy, A. A. Barnes, M. M. Eilert, L. Tcheang, D. Daniels, A. I. Muir, M. J. Wigglesworth, I. Kinghorn, N. J. Fraser, N. B. Pike, J. C. Strum, K. M. Steplewski, P. R. Murdock, J. C. Holder, F. H. Marshall, P. G. Szekeres, S. Wilson, D. M. Ignar, S. M. Foord, A. Wise, and S. J. Dowell. 2003. The Orphan G protein-coupled receptors GPR41 and GPR43 are activated by propionate and other short chain carboxylic acids. J. Biol. Chem. 278:11312-11319.

Capuco, A. V., S. Ellis, D. L. Wood, R. M. Akers, and W. Garrett. 2002. Postnatal mammary ductal growth: Three-dimensional imaging of cell proliferation, effects of estrogen treatment, and expression of steroid receptors in prepubertal calves. Tissue Cell 34:143-154.

Diano, M., A. Le Bivic, and M. Hirn. 1987. A method for the production of highly specific polyclonal antibodies. Anal. Biochem. 166:224-229.

Gorka, P., Z. M. Kowalski, P. Pietrzak, A. Kotunia, R. Kiljanczyk, J. Flaga, J. J. Holst, P. Guilloteau, and R. Zabielski. 2009. Effect of sodium butyrate supplementation in milk replacer and starter diet on rumen development in calves. J. Physiol. Pharmacol. 60(Suppl. 3):47-53.

Harmon, D. L. 1992. Impact of nutrition on pancreatic exocrine and endocrine secretion in ruminants: A review. J. Anim. Sci. 70:1290-1301.

Kaji, I., S. Karaki, R. Tanaka, and A. Kuwahara. 2011. Density distribution of free fatty acid receptor 2 (FFA2)-expressing and GLP-1-producing enteroendocrine L cells in human and rat lower intestine, and increased cell numbers after ingestion of fructo-oligosaccharide. J. Mol. Histol. 42:27-38.

Karaki, S., R. Mitsui, H. Hayashi, I. Kato, H. Sugiya, T. Iwanaga, J. B. Furness, and A. Kuwahara. 2006. Short-chain fatty acid receptor, GPR43, is expressed by enteroendocrine cells and mucosal mast cells in rat intestine. Cell Tissue Res. 324:353-360.

Karaki, S., H. Tazoe, H. Hayashi, H. Kashiwabara, K. Tooyama, Y. Suzuki, and A. Kuwahara. 2008. Expression of the short-chain fatty acid receptor, GPR43, in the human colon. J. Mol. Histol. 39:135-142.
Kristensen, N. B., and D. L. Harmon. 2004. Effect of increasing ruminal butyrate absorption on splanchnic metabolism of volatile fatty acids absorbed from the washed reticulorumen of steers. J. Anim. Sci. 82:3549-3559.

Lane, M. A., and B. W. Jesse. 1997. Effect of volatile fatty acid infusion on development of the rumen epithelium in neonatal sheep. J. Dairy Sci. 80:740-746.

Le Poul, E., C. Loison, S. Struyf, J. Y. Springael, V. Lannoy, M. E. Decobecq, S. Brezillon, V. Dupriez, G. Vassart, J. Van Damme, M. Parmentier, and M. Detheux. 2003. Functional characterization of human receptors for short chain fatty acids and their role in polymorphonuclear cell activation. J. Biol. Chem. 278:25481-25489.

Li, C. J., and T. H. Elsasser. 2005. Butyrate-induced apoptosis and cell cycle arrest in bovine kidney epithelial cells: Involvement of caspase and proteasome pathways. J. Anim. Sci. 83:89-97.

Li, R. W., and C. Li. 2006. Butyrate induces profound changes in gene expression related to multiple signal pathways in bovine kidney epithelial cells. BMC Genomics 7:234.

Nilsson, N. E., K. Kotarsky, C. Owman, and B. Olde. 2003. Identification of a free fatty acid receptor, FFA2R, expressed on leukocytes and activated by short-chain fatty acids. Biochem. Biophys. Res. Commun. 303:1047-1052.

Sakata, T., and H. Tamate. 1978. Rumen epithelial cell proliferation accelerated by rapid increase in intraruminal butyrate. J. Dairy Sci. 61:1109-1113.

Siciliano-Jones, J., and M. R. Murphy. 1989. Production of volatile fatty acids in the rumen and cecum-colon of steers as affected by forage:concentrate and forage physical form. J. Dairy Sci. 72:485-492.

Tang, Y., Y. Chen, H. Jiang, G. T. Robbins, and D. Nie. 2011. G-protein-coupled receptor for short-chain fatty acids suppresses colon cancer. Int. J. Cancer 128:847-856.

Wang, A., Z. Gu, B. Heid, R. M. Akers, and H. Jiang. 2009. Identification and characterization of the bovine $\mathrm{G}$ protein-coupled receptor GPR41 and GPR43 genes. J. Dairy Sci. 92:2696-2705.

Zhou, Y., A. V. Capuco, and H. Jiang. 2008. Involvement of connective tissue growth factor (CTGF) in insulin-like growth factor-I (IGF1) stimulation of proliferation of a bovine mammary epithelial cell line. Domest. Anim. Endocrinol. 35:180-189. 